\title{
IMPROVING THE PROPERTIES OF THE ASPHALT MIXTURE, BY CONTENT VARIATION OF THE BITUMEN
}

\author{
Beatrice Daniela TUDOR \\ "Dunarea de Jos" University of Galati, Romania \\ e-mail: btudor@ugal.ro
}

\begin{abstract}
The paper presents a study, on several samples of asphalt mix, with different compositions, in order to investigate the influence of the composition, on the properties, which asphalt mix must fulfil. For all kinds of aggregates, the granulometric analysis was made, and the bitumen content was varied, to study the influence on the properties of the mixture.
\end{abstract}

KEYWORDS: asphalt mixture, bitumen, granulometry, filler, quality

\section{Introduction}

The asphalt mix is a mixture of filler, fine and coarse stone granules, as well as bitumen, as a binder.

The bitumens are natural or artificial materials, of organic nature, of variable consistency (from viscous liquid to brittle solids), and the colour is brown-black. Bitumen mixed with mineral powders is called asphalt.

The hot asphalt mixture is a building material, made by a technological process, which involves heating the natural aggregates and bitumen, mixing, transporting, and putting into operation, usually by hot compaction.

The asphalt mixes are used for the wear layer, the bonding layer, as well as for the base layer. The production of asphalt mixtures can be done, by "hot" or "cold" technologies, depending on the binder used in their composition [1].

The technological process for the manufacture of hot asphalt mixtures comprises the following phases: pre-aggregating, heating, dosing and mixing the aggregates with bitumen in the mixer, at high temperatures.

The drying, heating, and dust removal from the aggregates are very important operations, since, in order to achieve a good coating with bitumen, they must have a suitable temperature, so that the hot binder, in contact with the aggregate, not to cool, but to remain fluid, to coating all the granules as evenly as possible.

The main factors to be considered in the drying and heating process are:

- humidity of the aggregates;

- their granulosity;
- the temperature required for coating.

The dosing and mixing are done so that asphalt mixtures can be made, as homogeneous as possible, respecting the dosages, given by the laboratory. The sorter-doser, aims at sifting the hot aggregates, separating them into fractions, thus reconstituting a mixture, perfectly dosed. It consists of several sieves, which allow the fractions to be sorted.

The hot aggregates, weighed by the metering dispenser, are introduced into the mixer. It adds the cold filler, seeking to achieve a better homogenization of the aggregates with the filler. Then it adds the binder (bitumen), hot, at $150 \ldots 170{ }^{\circ} \mathrm{C}$, and continue mixing. For mixing, the bitumen must be heated to $150 \ldots 170{ }^{\circ} \mathrm{C}$, to ensure a good viscosity.

Insufficient mixing, results in a heterogeneous distribution of the binder. Too much mixing, does not improve the coating, and decreases the efficiency of the installation [2, 4].

The heating of the aggregates and the bitumen, at very high temperatures (over $200{ }^{\circ} \mathrm{C}$ ), leads to transformations, which change the characteristics of the bitumen, being able to reach, at the "burning" of the bitumen, which is equivalent to the loss of adhesiveness and aging premature.

The quality control of the asphalt mix produced, is performed by the laboratory, which performs the analysis of the asphalt mix, determining the bitumen content and the granulosity of the aggregate.

\section{Experimental research}

For the research, I took into consideration, a number of 4 samples, in which I did the granulometric analysis, of the materials that enter the 
recipe of the mixture, and we varied the bitumen content, to study, how they influence the properties of the asphalt mixture, and which would be the optimum quantity of the bitumen, to obtain the best characteristics of the asphalt mixture [3].

Asphalt mixing, under laboratory conditions, involves the following steps:

Calculation of the dosages of material, for each variant of recipe, according to their characteristics.

The materials used in the preparation of the mixture are the following:

- Chippings with different degrees of size.

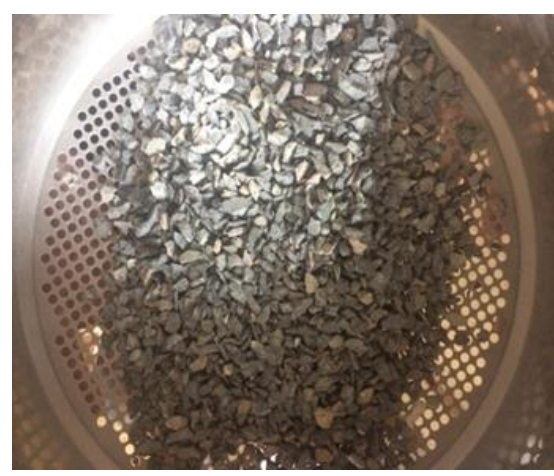

Fig. 1. Chipping 5-10 mm

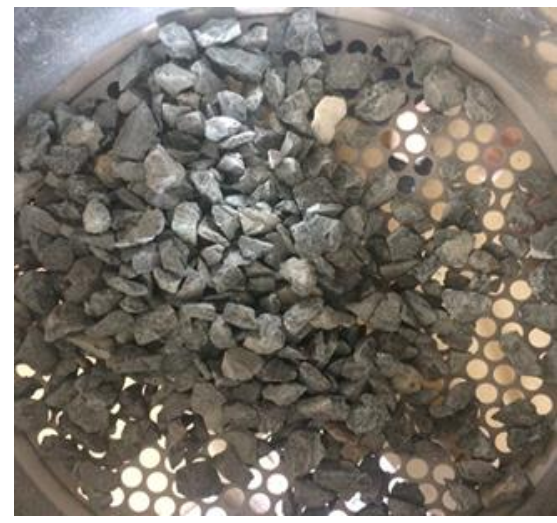

Fig. 2. Chipping 10-20 mm

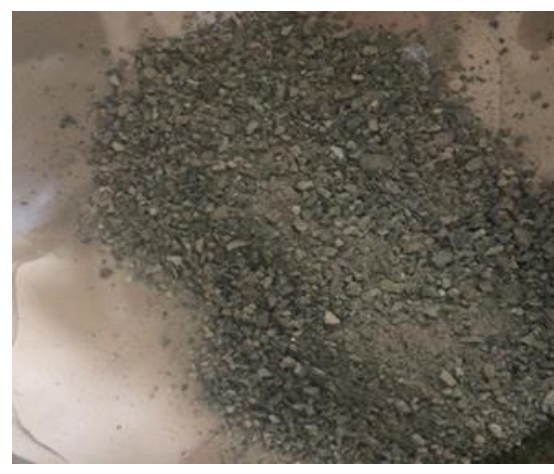

Fig. 3. Sand crushing 0-5 mm

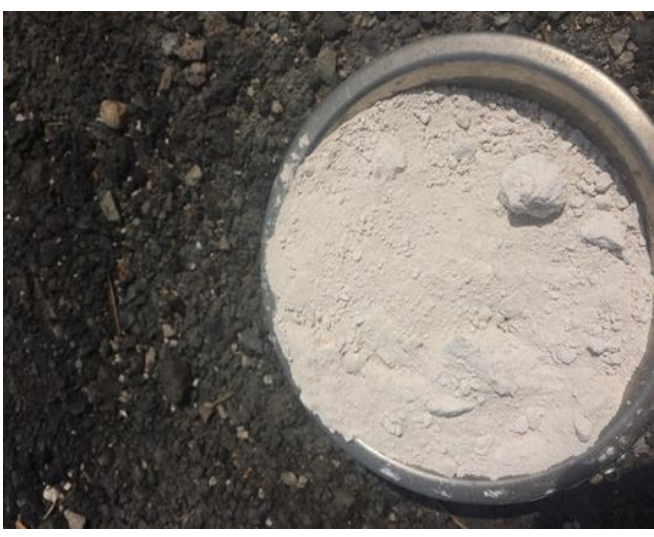

Fig. 4. Filler

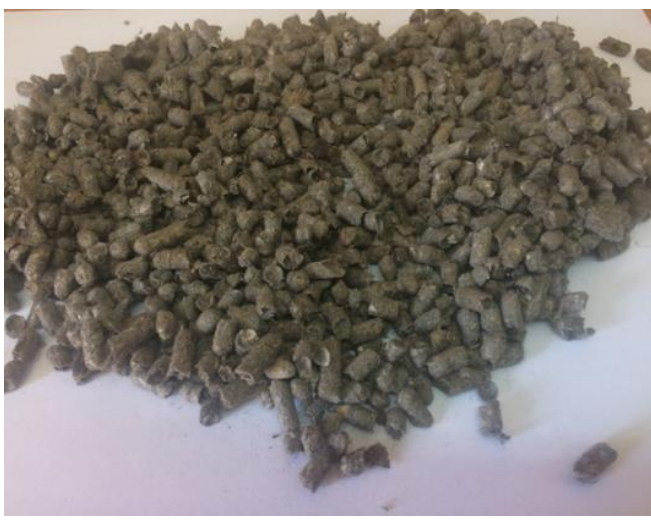

Fig. 5. Cellulose fiber

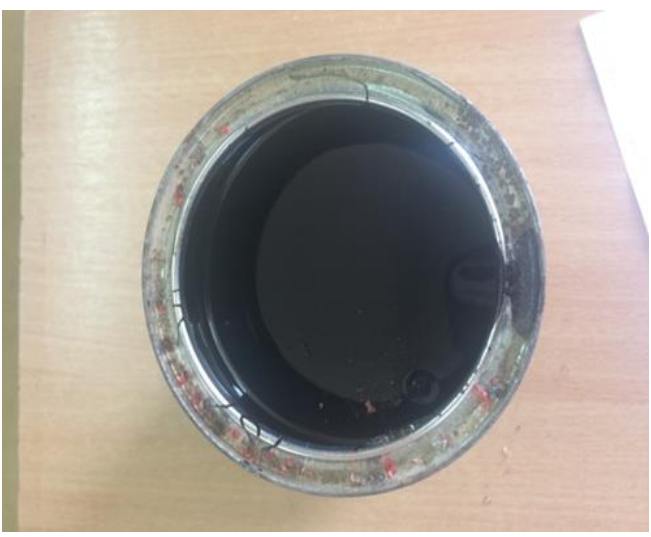

Fig. 6. Bitumen

Separately in a tray, the aggregates + the filler + fiber are weighing in the calculated dosages, for each sample and heat in the oven, at $160-170{ }^{\circ} \mathrm{C}$.

The bitumen is heated, in a thermoreglable oven, at temperatures of $140-150{ }^{\circ} \mathrm{C}$ (Fig. 8).

Preparation of the asphalt mixture - The prepared asphalt mixture, is transferred from the mixer into a tray, and is introduced in the oven (Fig. 7), to reach the temperature necessary to make the samples. 


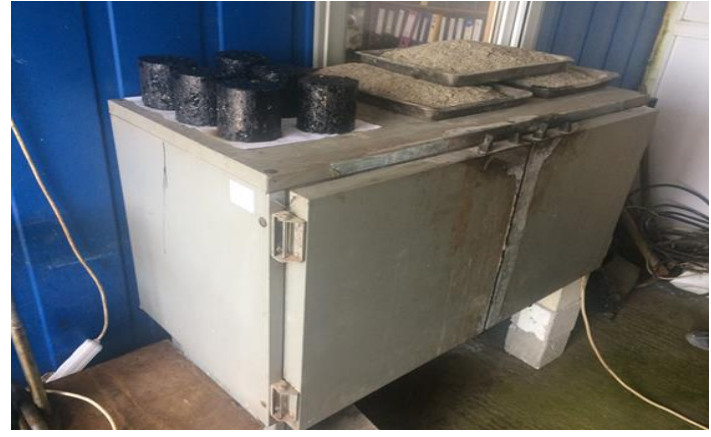

Fig. 7. Oven with adjustable heating

After all the steps of making asphalt samples are followed, they are subjected to tests, to see if they comply with the norms, then, the recipe of the mixture, is sent to the asphalt making station.

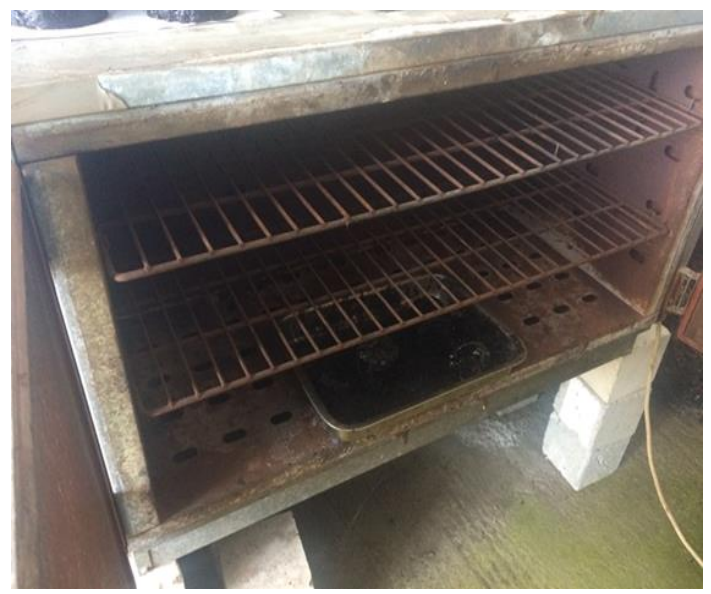

Fig. 8. Heating of bitumen, in a thermoreglable oven

The granulometric analysis of the materials is presented in the following tables.

Table 1. Sand crushing tests sort $0 / 5 \mathrm{~mm}$

\begin{tabular}{|c|c|c|}
\hline \multirow{4}{*}{ No } & Characteristics & Results obtained \\
\cline { 2 - 3 } & & Sample 1 \\
\hline \multirow{4}{*}{1} & Granulometry: & \\
\cline { 2 - 3 } & Passes\% on the sieve 10.0 & 100.0 \\
\cline { 2 - 3 } & Passes \% on the sieve 5 & 97.8 \\
\cline { 2 - 3 } & Passes \% on the sieve 2.5 & 65.3 \\
\cline { 2 - 3 } & Passes \% on the sieve 1.25 & 49.4 \\
\cline { 2 - 3 } & Passes \% on the sieve 0.63 & 31.0 \\
\cline { 2 - 3 } & Passes \% on the sieve 0.315 & 18.7 \\
\cline { 2 - 3 } & Passes \% on the sieve 0.140 & 9.6 \\
\cline { 2 - 3 } & Passes \% on the sieve 0.071 & 5.3 \\
\hline
\end{tabular}

Table 2. Tests on the chippings, sort 5/10 $\mathrm{mm}$

\begin{tabular}{|c|c|c|}
\hline \multirow{4}{*}{ No } & Characteristics & Results obtained \\
\cline { 2 - 3 } & Granulometry: & Sample 2 \\
\hline \multirow{7}{*}{1} & Passes \% on the sieve 40.0 & \\
\cline { 2 - 3 } & Passes \% on the sieve 20.0 & 100.0 \\
\hline & Passes \% on the sieve 10.0 & 99.1 \\
\hline & Passes \% on the sieve 7.5 & 66.3 \\
\hline & Passes \% on the sieve 5 & 8.7 \\
\hline & Passes \% on the sieve 2.5 & 1.6 \\
\hline & Passes \% on the sieve 1.25 & \\
\hline & Passes \% on the sieve 0.63 & \\
\hline & Passes \% on the sieve 0.315 & \\
\hline & Passes \% on the sieve 0.140 & \\
\hline & Passes \% on the sieve 0.071 & \\
\hline
\end{tabular}

Table 3. Tests on the chippings, sort 10/20 mm

\begin{tabular}{|c|c|c|}
\hline \multirow{4}{*}{ No } & Characteristics & $\begin{array}{c}\text { Results } \\
\text { obtained }\end{array}$ \\
\cline { 2 - 3 } & Granulometry: & Sample 3 \\
\hline \multirow{4}{*}{1} & Passes \% on the sieve 40.0 & 100.0 \\
\hline \multirow{4}{*}{} & Passes \% on the sieve 20.0 & 99.3 \\
\hline & Passes \% on the sieve 10.0 & 65.2 \\
\hline & Passes \% on the sieve 7.5 & 9.4 \\
\hline & Passes \% on the sieve 5 & 0.9 \\
\hline & Passes \% on the sieve 2.5 & \\
\hline & Passes \% on the sieve 1.25 & \\
\hline & Passes \% on the sieve 0.63 & \\
\hline & Passes \% on the sieve 0.315 & \\
\hline & Passes \% on the sieve 0.140 & \\
\hline & Passes \% on the sieve 0.071 & \\
\hline
\end{tabular}

Table 4. Tests on the filler (sample 4)

\begin{tabular}{|c|c|c|}
\hline \multicolumn{3}{|c|}{ Granulometric analysis } \\
\hline Sieve, mm & $\begin{array}{c}\% \\
\text { Passes }\end{array}$ & Limit \\
\hline 1.25 & 100 & $100 \%$ \\
\hline 0.63 & 100 & \\
\hline 0.315 & 99.9 & \\
\hline 0.14 & 93.9 & \\
\hline 0.071 & 77.2 & min. $70 \%$ \\
\hline
\end{tabular}

In order to control the quality of the asphalt mix, the samples were subjected to the following determinations: mean density, water saturation, and swelling.

For this, the samples were weighed, after the following steps: 
The dry test

- it leaves the sample in the water for one hour (Fig. 10);

- the sample is weighed in water;

- then, the sample is weighed in the air;

- the samples are placed in the suction vessel, with vacuum pump, for 3 hours (Fig. 9).

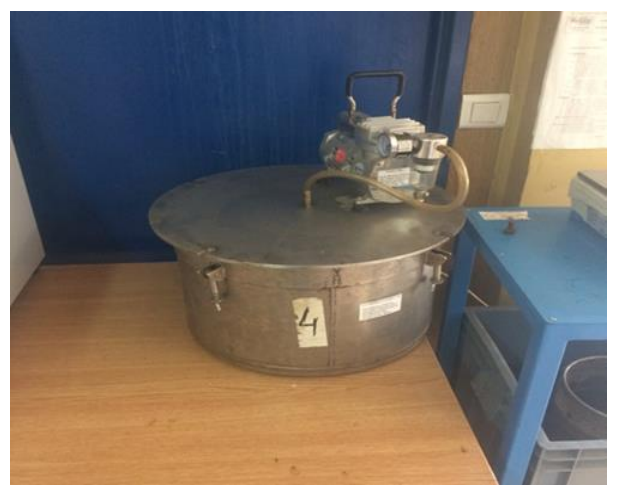

Fig. 9. Suction vessel, with vacuum pump

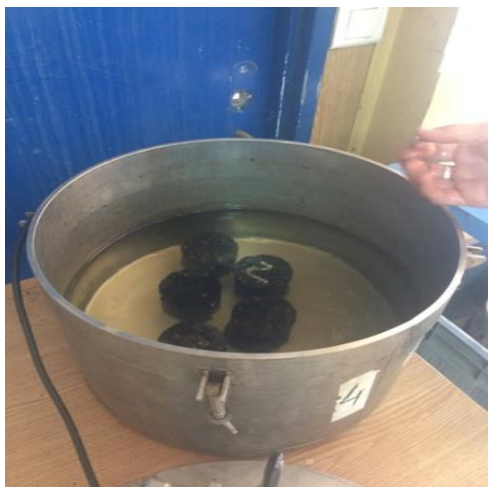

Fig. 10. Preparation of the samples for the absorption test

The results obtained are highlighted in the following graphs:

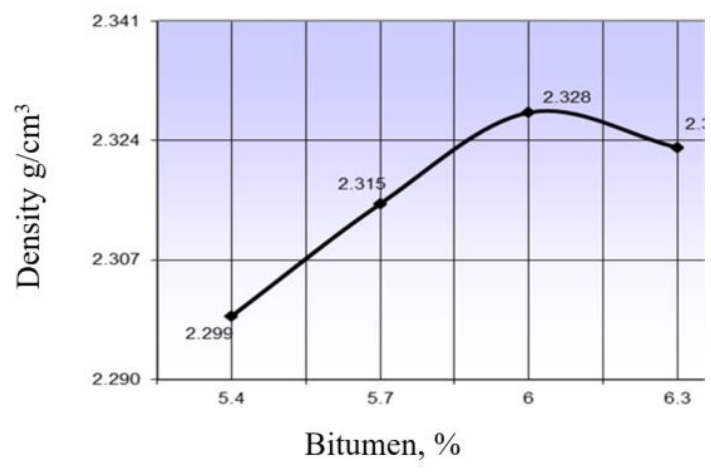

Fig. 11. The average density, of the asphalt mixing samples
A maximum of the average density, we found at the sample with $6 \%$ bitumen, and at the sample with $6.3 \%$ bitumen, the average density decreases (Fig. $11)$.

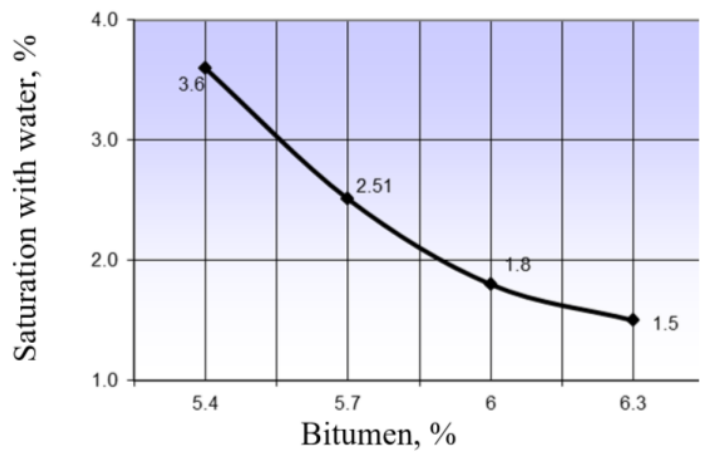

Fig. 12. Saturation with water, of the samples of asphalt

By studying the results at the 4 samples, with different content of bitumen, we found that the saturation with water of the samples decreases, with the increase of bitumen percentage (Fig. 12).

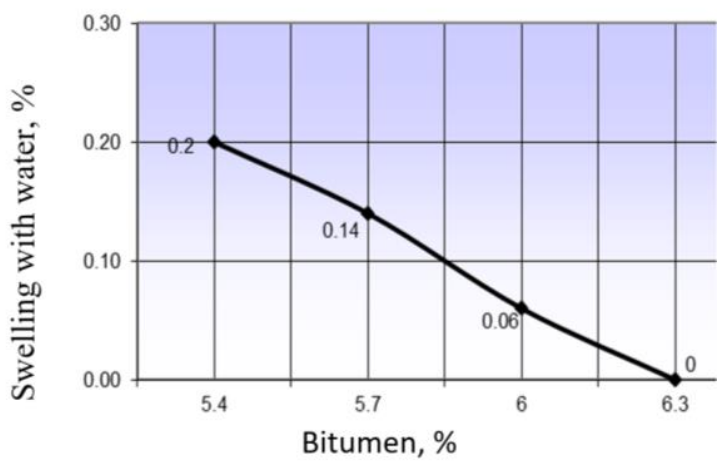

Fig. 13. Swelling with water of the asphalt mixing samples

The sample with a higher bitumen content, respectively $6.3 \%$, has the lowest water absorption, which is an advantage, for the final composition, because the asphalt becomes more resistant to moisture (Fig. 13).

\section{Conclusions}

The quality of the materials used in an asphalt mix, plays an important role, in the subsequent behavior and in the exploitation of the mix, so that for make up the mix should be used aggregates with high mechanical strength, bitumen with low susceptibility 


\section{THE ANNALS OF "DUNAREA DE JOS” UNIVERSITY OF GALATI \\ FASCICLE IX. METALLURGY AND MATERIALS SCIENCE \\ No. 2 - 2019, ISSN 2668-4748; e-ISSN 2668-4756 \\ Article DOI: https://doi.org/10.35219/mms.2019.2.05}

to the temperature variations, and an optimum percentage of filler $[5,6]$.

- Is establishing an optimum binder content, which ensures for the asphalt mix, the best characteristics, and a good behavior in operation.

-The most important problems, in the case of making good quality asphalt mixtures, is to establish, with an optimal bitumen content, and a rigorous particle size analysis at all the materials that make up the mix's recipe.

- The quality of the asphalt mixtures is one of the important factors, which determines the quality of the works for road construction, which first of all implies, satisfying the requirements of resistance, and safety in operation.

- For all kinds of aggregates, granulometric analysis was performed.

- For all 4 samples, we varied the bitumen content, for see, how was influenced the properties of the mixture.

- Following the tests, on the mixtures of asphalt mix, prepared in the laboratory, with the following bitumen dosages: 5.4\%; 5.7\%; $6.0 \%$; $6.3 \%$, determinations were made, of some physicalmechanical characteristics.

- For each test, the variation curve was drawn, with the increase of the bitumen dosage.

- The best properties were obtained at the sample with $6.0 \%$ bitumen.

\section{References}

[1]. West R. C., Watson D. E., Turner P. A., Casola J. R., Mixing and Compaction Temperatures of Asphalt Binders in HotMix Asphalt, NCHRP Report 648, Transportation Research Board, 2010.

[2]. Blażejowski K., Styk S., Technologia warstw asfaltowych, Wydawnictwa Komunikacji i Łączności, 2004.

[3]. ***, CONCAWE: Chemical Safety Report. Part B. "Bitumen" and "Oxidized Asphalt".

[4]. ***, Development in Asphalt Binder Specifications. Transportation Research Circular E-C147, Transportation Research Board, December 2010.

[5]. ***, Physical differentiation between air-rectified and oxidised bitumens, Technical Committee Task Force, Eurobitume, 15.04.2011.

[6]. ***, Une méthode ameliorèe de caractérisation des bitumes par leurs propriétés mechaniques, Heukelom W., Bull. Liaison Labo. P. et Ch., 76, p. 55-64, 1975. 